\title{
Presence of mycotoxins in sugar beet pulp silage collected in France
}

\author{
H. Boudra ${ }^{\mathrm{a}, *}$, B. Rouillé ${ }^{\mathrm{b}}$, B. Lyan ${ }^{\mathrm{c}}$, D.P. Morgavi ${ }^{\mathrm{a}}$ \\ a INRA, UMR1213 Herbivores, F-63122, Saint-Genès-Champanelle and Clermont Université, VetAgro Sup, UMR Herbivores, BP 10448, \\ F-63000 Clermont-Ferrand, France \\ b Institut de l'Elevage, Monvoisin, BP 85225, F-35652 Le Rheu Cedex, France \\ c INRA, UMR 1019, Plateforme d'Exploration du Métabolisme, Nutrition Humaine, F-63122 Clermont-Ferrand, \\ Saint-Genès-Champanelle, France
}

\section{A R T I C L E I N F O}

\section{Article history:}

Received 14 November 2014

Received in revised form 1 April 2015

Accepted 9 April 2015

\section{Keywords:}

Sugar beet pulp silage

Mycotoxins

LC-ESI-MS/MS

QuEChERS, Feed safety

\begin{abstract}
A B S T R A C T
Sugar beet pulp, a major by-product of the sugar industry, is a common feed component in cattle diets that is preserved on-farm as silage. This study was designed to investigate if sugar beet pulp silage could be a vehicle of common mycotoxins found in silages and other regulated mycotoxins. Samples $(n=40)$ favouring mouldy spots, if present, on the front face of open silages were collected in 2011 from 5 regions representing the main French sugar beet producing areas. Mycotoxins were extracted by QuEChERS procedure without any further clean-up and analyzed by liquid chromatography coupled with electrospray ionization tandem mass spectrometry (LC-ESI-MS/MS). The mycotoxins monitored were: aflatoxin B1, deoxynivalenol, gliotoxin, ochratoxin A, mycophenolic acid, patulin, penicillic acid, roquefortine $C$ and zearalenone. Matrix-matched calibrations were used, yielding acceptable levels of recovery ranging from 64 to $168 \%$, except for gliotoxin and roquefortine $C$ for which recovery was lower ( 21 and $34 \%$, respectively). Eight samples out of 40 (20\%) were found to be positive. Mycophenolic acid and zearalenone were the most predominant of the mycotoxins studied. Mycophenolic acid was found in five of 40 samples at levels ranging from traces up to $1436 \mu \mathrm{g} / \mathrm{kg}$. Zearalenone was found in three samples at concentrations of 1023,4862 and $6916 \mu \mathrm{g} / \mathrm{kg}$. The last 2 samples were at concentrations above the recommended limit of $2000 \mu \mathrm{g} / \mathrm{kg}$. Ochratoxin A was detected in one sample at $15 \mu \mathrm{g} / \mathrm{kg}$, which is below the recommended EU limit of $250 \mu \mathrm{g} / \mathrm{kg}$. Roquefortine $\mathrm{C}$ was also detected but at low levels. To our knowledge, this study is the first to report on the presence of mycotoxins in sugar beet pulp silage. Contamination for the tested mycotoxins was low and did not seem to present a health risk for animals or consumers for the tested mycotoxins.
\end{abstract}

(c) 2015 Elsevier B.V. All rights reserved.

\section{Introduction}

Sugar beet (Beta vulgaris L.) is an important industrial crop in temperate regions that provides about a third of all sugar consumed in the world. France is one of the main producers of sugar beet in Europe, with 34 million tonnes harvested in 2009 (http://www.labetterave.com). Due to its nutritional value and availability, the sugar beet pulp by-product of the

\footnotetext{
* Corresponding author. Tel.: +33 47362 4104; fax: +33 473624659

E-mail address: abdelhamid.boudra@clermont.inra.fr (H. Boudra).
} 
sugar industry is widely used by farmers in production areas. The sugar beet pulp is ensiled on the farm and incorporated into cattle diets. One common risk affecting silage conservation and quality is the development of fungi which reduces the nutritive value of feeds and animal performances (Morgavi et al., 2008; Boudra, 2009). In addition, fungal development can be accompanied by production of mycotoxins that can affect animal health. The most common infestation of sugar beet in the field is caused by Fusaria, and some species are capable of producing mycotoxins in the field (Hanson, 2006; Nitschke et al., 2009; Hill et al., 2011) and in vitro (Bosch and Mirocha, 1992; Burlakoti et al., 2008; Christ et al., 2011). In addition to Fusarium spp. that cause losses in the field, Aspergillus and Penicillium species can grow when silage is not appropriately conserved (Binder et al., 2007; Boudra, 2009). Information on sugar beet contamination with mycotoxins is sparse. Bosch and Mirocha (1992) reported that 6 out of 25 moldy sugar beet samples collected in the field contained zearalenone (ZEA) in concentrations ranging between 12 and $391 \mu \mathrm{g} / \mathrm{kg}$. Zearalenone was also detected in 31 out of 75 sugar beet fiber samples (13 to $47 \mu \mathrm{g} / \mathrm{kg}$ ) (Bosch and Mirocha, 1992). To our knowledge, there is just a single report on fungal contamination of stored sugar beet pulp silage (Nout et al., 1993), but the presence of corresponding mycotoxins was not investigated. The aim of the study reported here was to assess the risk of mycotoxin contamination in sugar beet pulp silage samples collected from the 5 main areas of sugar beet production in France. The method developed in this study targeted mycotoxins that were frequently found in silages: patulin (PAT), penicillic acid (PENI), gliotoxin (GLIO), roquefortine C (ROQ C), and mycophenolic acid (MYCO) (Auerbach et al., 1998; Richard et al., 2007; Mansfield et al., 2008; Rasmussen et al., 2010; Van Pamel et al., 2011), in addition to aflatoxin B1 (AFB1), ochratoxin A (OTA), deoxynivalenol (DON), and zearalenone (ZEA) that are regulated in feeds in the European Union (European Commission, 2006).

\section{Materials and methods}

\subsection{Sample collection}

Sugar beet pulp silage samples were collected from 5 regions: Haute-Normandie $(n=11)$, Ile-de-France $(n=9)$, Picardie $(n=7)$, Nord-Pas-de-Calais $(n=8)$, and Centre $(n=5)$, representing the main areas of sugar beet production in France (http://agreste.agriculture.gouv.fr/). Silages from each region were from one sugar production plant. All production plants used high pressure technology to extract sugar from beet root and the pulp was transported immediately to farms for ensiling within the same day. Samples were taken from silos that were in current use at five places on the front face, on a diagonal line from one upper corner to the opposite bottom corner. While respecting this sampling procedure, operators were instructed to favour moldy spots if present on the front face. This was done as the objective was to assess the risk of mycotoxins contamination from this feed resource. Samples were then pooled and a subsample of $150 \mathrm{~g}$ was sent to the laboratory within $24 \mathrm{~h}$ for mycological and mycotoxin analysis. Farms included in this study had bunker silos with capacities of between 100 and $750 \mathrm{~m}^{3}$ and did not use preservatives for silage making. The dry matter (DM) of sugarbeet silage was determined in triplicate by drying at $105^{\circ} \mathrm{C}$ for $24 \mathrm{~h}$, and ranged from 19 to $28 \%$.

\subsection{Mycological analysis}

Ten grams of fresh sample were transferred into a sterile plastic bag, suspended in $90 \mathrm{ml}$ of sterile $0.05 \%$ Tween 80 , and homogenized for $5 \mathrm{~min}$ in a laboratory Stomacher blender (BayMixer 400, Interscience, Saint Nom la Breteche, France). Serial dilutions from $10^{-2}$ to $10^{-5}$ were made and $0.1 \mathrm{ml}$ of each was inoculated in duplicate in two different culture media: $2 \%$ Malt extract with and without sodium chloride. The plates were incubated at $25^{\circ} \mathrm{C}$ in the dark, and molds and yeasts were counted after three days of incubation. The results were expressed as colony-forming units (CFU)/g DM. The remainder of the sample was dried in a forced draft oven at $50{ }^{\circ} \mathrm{C}$ for two days, ground through a $1 \mathrm{~mm}$ sieve and stored at $+4{ }^{\circ} \mathrm{C}$ until mycotoxin analysis.

\subsection{Mycotoxin analysis}

Extraction of selected mycotoxins was performed by the QuEChERS (Quick, Easy, Cheap, Effective, Rugged, and Safe) method according to the original Waters procedure based on the AOAC method in two different steps. Briefly, six grams of silage were placed in a $50 \mathrm{ml}$-DisQuE ${ }^{\mathrm{TM}}$ tube $(186004837$, Waters) containing trisodium citrate dihydrate ( $1 \mathrm{~g})$, disodium hydrogencitrate sesquihydrate $(0.5 \mathrm{~g}), \mathrm{NaCl}(1 \mathrm{~g})$ and $\mathrm{MgSO}_{4}(4 \mathrm{~g})$. Five milliliter of distilled water containing $1 \%$ of acetic acid were added. After complete absorption of water, $10 \mathrm{ml}$ of $1 \%$ of acetic acid in acetonitrile were added and tubes were shaken vigorously for $1 \mathrm{~min}$, and then centrifuged ( $2000 \mathrm{~g}, 5 \mathrm{~min}$ ). One $\mathrm{ml}$ aliquot of the upper phase (corresponding to $0.4 \mathrm{~g}$ of silage) was transferred to a second 2-ml-DisQuE ${ }^{\mathrm{TM}}$ tube (186004837, Waters) containing $0.15 \mathrm{~g}$ MgSO 4 and $0.025 \mathrm{~g}$ PSA (primary secondary amine). We added $7.5 \mathrm{mg}$ of Graphitized Carbon Black (DisQuE ${ }^{\mathrm{TM}}, 186004837$, Waters) to each tube in order to remove pigments such as carotenoids and chlorophyll from the samples. Samples were shaken vigorously for 1 min and then centrifuged $(2000 \mathrm{~g}, 5 \mathrm{~min})$. The upper phase was filtered through a $0.45 \mu \mathrm{m}$ filter, and $10 \mu \mathrm{l}$ were injected into the LC system. The chromatographic system was an Alliance 2695 module (Waters Corporation, St-Quentin-en-Yvelines, France). Separation was performed at room temperature on a $\mathrm{C}_{18}$ RP column (Luna, $50 \times 2 \mathrm{~mm}$, $3 \mu \mathrm{m}$, Phenomenex, Paris, France) using a gradient solvent system (solvent $\mathrm{A}=0.1 \%$ formic acid-ammonium acetate $0.5 \mathrm{mM}$ adjusted to $\mathrm{pH} 3.5$, and solvent $\mathrm{B}=$ Acetonitrile- $0.1 \%$ formic acid). The gradient conditions were as follows: the initial percentage of solvent $\mathrm{B}$ was 
Table 1

Transition reactions monitored by LC-ESI-MS/MS, cone and collision voltages

\begin{tabular}{|c|c|c|c|c|c|c|}
\hline Metabolites & $\operatorname{Tr}$ & Ionisation mode & Precursor ion & Daughter ion & Cone voltage (V) & Collision energy $(\mathrm{eV})$ \\
\hline \multirow[t]{2}{*}{ Patulin } & \multirow[t]{2}{*}{11.08} & \multirow[t]{2}{*}{ ESI- } & \multirow[t]{2}{*}{153.0} & 81 & 15 & 13 \\
\hline & & & & 109 & 15 & 9 \\
\hline \multirow[t]{2}{*}{ Deoxynivalenol } & \multirow[t]{2}{*}{2.28} & \multirow[t]{2}{*}{ ESI- } & \multirow[t]{2}{*}{341.0} & 265 & 15 & 11 \\
\hline & & & & 295.0 & 15 & 9 \\
\hline \multirow[t]{2}{*}{ Penicillic acid } & \multirow[t]{2}{*}{6.08} & \multirow[t]{2}{*}{ ESI- } & \multirow[t]{2}{*}{169.0} & 93 & 20 & 19 \\
\hline & & & & 110.0 & 20 & 9 \\
\hline \multirow[t]{2}{*}{ Gliotoxin } & \multirow[t]{2}{*}{9.55} & \multirow[t]{2}{*}{ ESI+ } & \multirow[t]{2}{*}{327.1} & 245.29 & 15 & 17 \\
\hline & & & & 263.241 & 15 & 9 \\
\hline \multirow[t]{2}{*}{ Aflatoxin B1 } & \multirow[t]{2}{*}{11.41} & \multirow[t]{2}{*}{ ESI+ } & \multirow[t]{2}{*}{313.0} & 128 & 45 & 60 \\
\hline & & & & 285.1 & 45 & 21 \\
\hline \multirow[t]{2}{*}{ Roquefortine C } & \multirow[t]{2}{*}{10.26} & \multirow[t]{2}{*}{ ESI+ } & \multirow[t]{2}{*}{390.2} & 193.29 & 35 & 27 \\
\hline & & & & 322.228 & 35 & 19 \\
\hline \multirow{2}{*}{ Mycophenolic acid } & \multirow[t]{2}{*}{11.91} & \multirow[t]{2}{*}{ ESI+ } & \multirow[t]{2}{*}{321.2} & 207 & 20 & 19 \\
\hline & & & & 303.211 & 29 & 9 \\
\hline \multirow[t]{2}{*}{ Zearalenone } & \multirow[t]{2}{*}{13.23} & \multirow[t]{2}{*}{ ESI+ } & \multirow[t]{2}{*}{319.2} & 97 & 20 & 17 \\
\hline & & & & 301.294 & 20 & 9 \\
\hline \multirow[t]{2}{*}{ Ochratoxin A } & \multirow[t]{2}{*}{13.43} & \multirow[t]{2}{*}{ ESI+ } & \multirow[t]{2}{*}{404.1} & 239.19 & 25 & 23 \\
\hline & & & & 358.19 & 25 & 13 \\
\hline
\end{tabular}

Transition in bold used for quantification.

Table 2

Parameters of the method tested for sugar beet samples.

\begin{tabular}{|c|c|c|c|}
\hline \multirow[t]{3}{*}{ Mycotoxins } & \multicolumn{3}{|c|}{ Parameters of method } \\
\hline & \multirow{2}{*}{$\begin{array}{l}\text { SSE } \\
(\%)\end{array}$} & \multicolumn{2}{|c|}{ Range of calibration } \\
\hline & & $\left(\mathrm{ng} \mathrm{ml}^{-1}\right)$ & Recovery (\%) \\
\hline Aflatoxin B1 & 78 & $1.25-6.25$ & $73 \pm 3$ \\
\hline Ochratoxin A & 89 & & $64 \pm 5$ \\
\hline Zearalenone & 187 & & $137 \pm 43$ \\
\hline Mycophenolic acid & 96 & & $168 \pm 21$ \\
\hline Deoxynivalenol & 4 & & $45 \pm 18$ \\
\hline Roquefortine C & 62 & $50-250$ & $34 \pm 2$ \\
\hline Gliotoxin & 77 & & $21 \pm 3$ \\
\hline Patulin & 102 & & $131 \pm 4$ \\
\hline Penicillic acid & 45 & & $102 \pm 3$ \\
\hline
\end{tabular}

SSE, specific signal suppression and enhancement was calculated according to the following equation: (Slope of extract/Slope pure standard) $\times 100$.

$2 \%$, held at $2 \%$ for $4 \mathrm{~min}$, increased to $80 \%$ over $12 \mathrm{~min}$ and maintained for $8 \mathrm{~min}$. It was then lowered to the initial percentage in $0.1 \mathrm{~min}$, and maintained for $6 \mathrm{~min}$ to re-equilibrate the column prior to the next injection. The flow rate was $0.2 \mathrm{ml} \mathrm{min}{ }^{-1}$. Under such conditions, all mycotoxins and the internal standard (IS) were well separated. Electrospray mass spectrometric (ESI-MS/MS) analyses were performed on a Quattro Micro triple quadrupole mass spectrometer (Waters Corporation, StQuentin-en-Yvelines, France) equipped with an electrospray source operating in positive and negative ion modes. Capillary voltage was set at $4 \mathrm{kV}$, source temperature at $120^{\circ} \mathrm{C}$, and desolvatation temperature at $450{ }^{\circ} \mathrm{C}$. The cone and nebulization gas flows (both nitrogen) were set at 50 and $500 \mathrm{l} \mathrm{h}^{-1}$, respectively. Data were acquired using the multiple reaction monitoring (MRM) scanning mode. The values of the tune parameters were separately optimized by infusing a solution of each analyte at $10 \mu \mathrm{g} \mathrm{ml}^{-1}$ in mobile phase at a flow rate of $10 \mu \mathrm{min}^{-1}$. All mycotoxins selected showed greater sensitivity in ESI+, with the exception of DON, PENI and PAT which showed greater sensitivity in ESI-. Runs were therefore performed in both positive and negative modes. The MRM transitions and cone voltages and collision energies applied are summarized in Table 1. The most intense transition reaction was used for quantification purposes and the second was used for analyte confirmation. The matrix effect, evaluated by determination of enhancement of ion suppression, showed wide variability. The mass spectrometry signal was reduced for DON and PENI, and strongly enhanced for ZEA (Table 2). Matrix-matched calibrations were therefore used, giving acceptable rates of recovery ranging from 64 to 168 , except for GLIO and ROQ for which recovery was lower (21 and 34\%, respectively). The concentration of each mycotoxin was calculated using the following formula: Concentration $(\mu \mathrm{g} / \mathrm{kg})=M_{\mathrm{g}} / M_{\mathrm{s}}$, where $M_{\mathrm{g}}$ is the mass of mycotoxins ( $\left.\mu \mathrm{g}\right)$, and $M_{\mathrm{s}}$ the mass of the sugar beet pulp silage injected $(\mathrm{kg})$ into the LC-MS/MS system.

\section{Results and discussion}

Forty French farms were surveyed in 2011 for the presence of molds and mycotoxins in sugar beet pulp silage. As expected from the sampling protocol, mycological analysis revealed a high proportion of samples with counts exceeding the standard limit of hygienic quality of $5 \times 10^{4} \mathrm{CFU} / \mathrm{g}$ (34/40, 85\%) according to Le Bars (1989) (Table 3). This high level of contamination is 
Table 3

Occurrence of molds, yeasts and mycotoxins in sugar beet silage collected from French farms in 2011.

\begin{tabular}{|c|c|c|c|c|c|c|c|c|c|}
\hline \multirow[t]{2}{*}{ Origin } & \multirow{2}{*}{$\begin{array}{l}\text { Samples } \\
\text { analyzed }\end{array}$} & \multicolumn{8}{|c|}{ Mycotoxin ${ }^{\mathrm{a}}$ concentration $(\mu \mathrm{g} / \mathrm{kg})$} \\
\hline & & Positive & Molds & Yeasts & Mycotoxins & Ochratoxin A & Zearalenone & $\begin{array}{l}\text { Mycophenolic } \\
\text { acid }\end{array}$ & Roquefortine $\mathrm{C}$ \\
\hline Ile-de France & 9 & 7 & 3 & 4 & 1 & $1(15)$ & & trace & \\
\hline $\begin{array}{l}\text { Haute- } \\
\text { Normandie }\end{array}$ & 11 & 11 & 7 & 9 & 5 & & $1(1023)$ & $\begin{array}{l}4(\text { trace }, 116, \\
224,1436)\end{array}$ & $2(23,264)$ \\
\hline Picardie & 7 & 6 & 2 & 5 & 2 & & $2(4862,6916)$ & & \\
\hline $\begin{array}{l}\text { Nord-Pas-de- } \\
\text { Calais }\end{array}$ & 8 & 5 & 1 & 5 & 0 & & & & \\
\hline Centre & 5 & 5 & 1 & 4 & 0 & & & & \\
\hline All & 40 & 34 & 14 & 27 & 8 & & & & \\
\hline
\end{tabular}

a Mycotoxins that were tested with no positive samples: deoxynivalenol, gliotoxin, patulin, penicillic acid and aflatoxin.

certainly due to sampling of visibly moldy samples. In 7 samples there was co-occurrence of yeasts and molds. The incidence of yeast contamination (68\%) was greater than that of molds (35\%) probably because sampled silages had a relatively low DM (<28\%). A condition that favors yeast development as reported for other type of silages (Driehuis and Oude Elferink, 2000). Although yeasts do not produce mycotoxins, they indicate the quality of silage, including the risk of mycotoxin contamination.

The presence of mycotoxins is shown in Table 3. Eight out of 40 samples (20\%) were contaminated with four mycotoxins (OTA, ZEA, MYCO and ROQ C). MYCO and ZEA were the most predominant; MYCO was found in five out 40 samples at levels ranging from traces up to $1436 \mu \mathrm{g} \mathrm{kg}^{-1}$ while ZEA was found in three samples, two of them exceeding the recommended level of $2000 \mu \mathrm{g} \mathrm{kg}^{-1}$ set by European regulations (European Commission, 2006). This difference in mycotoxin contamination was probably due to farm management practices, especially the ensiling process and the rate of silage utilisation, both of which were under control of the farmer. OTA was detected in only one sample at $15 \mu \mathrm{g} \mathrm{kg}^{-1}$, which is below the recommended limit of $250 \mu \mathrm{g} \mathrm{kg}^{-1}$. ZEA is produced by Fusarium spp that mainly contaminates crop plants in the field before harvest. Several reports have shown that Fusarium spp are the main genera infesting sugar beet in the field (Bosch and Mirocha, 1992; Nout et al., 1993; Hanson, 2006; Burlakoti et al., 2008; Nitschke et al., 2009; Christ et al., 2011; Hill et al., 2011). We cannot exclude the production of ZEA during storage but this toxin, that was also detected in sugar beet samples collected in the field (Bosch and Mirocha, 1992), is known to be stable during the ensiling process (Kalac and Woollford, 1982; Lepom, 1988; Oldenburg, 1991; Boudra and Morgavi, 2008). The high concentration of ZEA found in two samples could potentially have a negative effect on reproductive efficiency. This is independent of the mycotoxin origin as mouldy parts of silage are not systematically removed. In addition to ZEA, there were three mycotoxins that are typically produced during storage, i.e. OTA, MYCO and ROQ C. MYCO and ROQ C have already been found in maize and grass silage (Müller and Amend, 1997; Auerbach et al., 2000; Rasmussen et al., 2010) but the presence of OTA has never been reported in silage. Although we have not tested for the presence of mycotoxins before ensiling, the types of mycotoxins found suggest that contamination could be originated both in the field and during storage. Field contamination is difficult to control as it depends on weather conditions. For those mycotoxins that are produced during storage, it is clear that awareness and training for farmers in good ensiling techniques should reduce the risk of contamination.

In conclusion, mycotoxins were detected in sugar beet pulp silage in France. However, the prevalence and types of mycotoxins found in this particular survey did not suggest a high risk for cattle and consumer health. Complementary studies under different conditions and covering other mycotoxins are needed to confirm the low-risk mycotoxin status of sugar beet pulp silage.

\section{Conflict of interest statement}

There is no conflict of interest in this work.

\section{Acknowledgements}

Part of this work was supported financially by the Comité National des Coproduits (Paris, France). We thank Serge Hamelin from "Contrôle Laitier d'Ile-de-France" for his assistance in providing the silage samples, and Delphine Delabre from INRA (Clermont-Theix) for her technical assistance.

\section{References}

Auerbach, H., Oldenburg, E., Pahlow, G., 2000. Prevention of Penicillium roqueforti-associated aerobic deterioration of maize silage by various additives. Mycotoxin Res. 16 A, 146-149.

Auerbach, H., Oldenburg, E., Weissbach, F., 1998. Incidence of Penicillium roqueforti and roquefortine C in silages. J. Sci. Food Agric. 76, 565-572. 
Binder, E.M., Tan, L.M., Chin, L.J., Handl, J., Richard, J., 2007. Worldwide occurrence of mycotoxins in commodities, feeds and feed ingredients. Anim. Feed Sci. Technol. 137, 265-282.

Bosch, U., Mirocha, C.J., 1992. Toxin production by Fusarium species from sugar beets and natural occurrence of zearalenone in beets and beet fibers. Appl. Environ. Microbiol. 58, 3233-3239.

Boudra, H., 2009. Mycotoxins: an insidiously menacing factor for the quality of forages and the performances of the ruminants. Fourrages $199,265-280$.

Boudra, H., Morgavi, D.P., 2008. Reduction in Fusarium toxin levels in corn silage with low dry matter and storage time. J. Agric. Food Chem. 56, $4523-4528$.

Burlakoti, R.R., Ali, S., Secor, G.A., Neate, S.M., McMullen, M.P., Adhikari, T.B., 2008. Comparative mycotoxin profiles of Gibberella zeae populations from barley, wheat, potatoes, and sugar Beets. Appl. Environ. Microbiol. 74, 6513-6520.

Christ, D.S., Märländer, B., Varrelmann, M., 2011. Characterization and mycotoxigenic potential of Fusarium species in freshly harvested and stored sugar beet in Europe. Phytopathology 101, 1330-1337.

Driehuis, F., Oude Elferink, S.J.W.H., 2000. The impact of the quality of silage on animal health and food safety: a review. Vet. Q. $22,212-216$.

European Commission, 2006. Commission Recommendation No 2006/576 of 17 August 2006 on the Presence of Deoxynivalenol, Zearalenone, Ochratoxin A, T-2 and HT-2 and Fumonisins in Products Intended for Animal Feeding, Available at /http://eur-lex.europa.eu/legal-content/EN/TXT/PDF/〉, (L 229/7, 7-9).

Hanson, L.E., 2006. Fusarium yellowing of sugar beet caused by Fusarium graminearum from Minnesota and Wyoming. Plant Dis. 90, 686.

Hill, A.L., Reeves, P.A., Larson, R.L., Fenwick, A.L., Hanson, L.E., Panella, L., 2011. Genetic variability among isolates of Fusarium oxysporum from sugar beet. Plant Pathol. 60, 496-505.

Kalac, P., Woollford, M.K., 1982. A review of some aspects of possible associations between the feeding of silage and animal health. Br. Vet. J. 138, 305-320.

Le Bars, J., 1989. In: AFTAA (Ed.), Aspects réglementaires: Normes pour les examens mycologiques et mycotoxicologiques et recommandations pour les prélèvements. AFTAA, Paris, France, pp. 45-52.

Lepom, P., 1988. Occurrence of Fusarium species and their mycotoxins in maize-method of determining zearalenone in maize and maize silage by means of HPLC with fluorescence detection. Arch. Anim. Nutr. 38, 799-806.

Mansfield, M.A., Jones, A.D., Kuldau, G.A., 2008. Contamination of fresh and ensiled maize by multiple Penicillium mycotoxins. Phytopathology 98, 330-336.

Morgavi, D.P., Boudra, H., Jouany, J.P., 2008. Consequences of mycotoxins in ruminant production. In: Oswald, I.P., Taranu, I. (Eds.), Mycotoxins in Farm Animals. Transword Research Network, Kerala, India, pp. 29-46.

Müller, H.M., Amend, R., 1997. Formation and disappearance of mycophenolic acid, patulin, penicillic acid and PR toxin in maize silage inoculated with Penicillium roqueforti. Arch. Anim. Nutr. 50, 213-225.

Nitschke, E., Nihlgard, M., Varrelmann, M., 2009. Differentiation of Eleven Fusarium spp. isolated from sugar beet. Using restriction fragment analysis of a polymerase chain reaction-amplified translation elongation factor $1 \alpha$ gene fragment. Phytopathology 99, 921-929.

Nout, M.J.R., Bouwmeester, H.M., Haaksma, J., Van Dijk, H., 1993. Fungal growth in silages of sugarbeet press pulp and maize. J. Agric. Sci. 121, 323-326.

Oldenburg, E., 1991. Mycotoxins in conserved forage. In: Conference on Forage Conservation Towards 2000, 23-25 January, Braunschweig, pp. 191-206.

Rasmussen, R., Storm, I., Rasmussen, P., Smedsgaard, J., Nielsen, K., 2010. Multi-mycotoxin analysis of maize silage by LC-MS/MS. Anal. Bioanal. Chem. 397, $765-776$.

Richard, E., Heutte, N., Sage, L., Pottier, D., Bouchart, V., Lebailly, P., Garon, D., 2007. Toxigenic fungi and mycotoxins in mature corn silage. Food Chem. Toxicol. 45, 2420-2425.

Van Pamel, E., Verbeken, A., Vlaemynck, G., De Boever, J., Daeseleire, E., 2011. Ultrahigh-performance liquid chromatographic-tandem mass spectrometric multimycotoxin method for quantitating 26 mycotoxins in maize silage. J. Agric. Food Chem. 59, 9747-9755.

\section{Web reference:}

http://www.labetterave.com/la_filiere_betteraviere/chiffres_cles/chiffres_cles_france/87/index.htm (accessed date: 29/07/2014). 